\begin{tabular}{|l|l|l||}
\hline \multicolumn{2}{|c|}{ PublisherInfo } \\
\hline \hline PublisherName & $:$ & BioMed Central \\
\hline \hline PublisherLocation & $:$ & London \\
\hline \hline PublisherImprintName & $:$ & BioMed Central \\
\hline \hline
\end{tabular}

\title{
Ranitidine or sucralfate for prevention of stress ulceration
}

\begin{tabular}{|l|l|l||}
\hline \multicolumn{2}{|c||}{ ArticleInfo } \\
\hline \hline ArticleID & $:$ & 4265 \\
\hline \hline ArticleDOI & $:$ & $10.1186 /$ ccf-2001-2861 \\
\hline \hline ArticleCitationID & $:$ & 2861 \\
\hline \hline ArticleSequenceNumber & $:$ & 53 \\
\hline \hline ArticleCategory & $:$ & Paper Report \\
\hline \hline ArticleFirstPage & $:$ & 1 \\
\hline \hline ArticleLastPage & $:$ & 4 \\
\hline \hline & & RegistrationDate : 2001-1-30 \\
\hline ArticleHistory & $:$ & OnlineDate \\
\hline ArticleCopyright & $:$ & Biomed Central Ltd2001-30 \\
\hline \hline ArticleGrants & $:$ & \\
\hline \hline ArticleContext & $:$ & 1305433 \\
\hline \hline
\end{tabular}




\section{Keywords}

Nosocomial infections, pneumonia, ranitidine, stress, sucralfate, ulcer

\section{Comments}

Meta-analyses depend upon having trials with large numbers of patients. In this meta-analysis, however, a number of the trials had low numbers of patients - between 20 and 40 in each group.

There were four other methodological problems. Firstly, the trials did not have the power to demonstrate any significant difference between the groups. Secondly, the end points of the trials were very different. Thirdly, one has to question the accuracy of the 'methodological quality score' because the studies had disparate entry criteria, variable dosing of drugs, alternate routes of administration, and different criteria of bleeding and pneumonia. Fourthly, and most importantly for the prevention of stress ulceration prevention, few of the trials account for disease stratification and factors such as enteral/ parenteral nutrition, the presence of renal impairment and/or failure, infection, and disseminated intravascular coagulopathy and thrombocytopaenia.

In conclusion, the overview of trials of ranitidine and sucralfate against placebo shows poor effectiveness in the prevention of stress ulcer. From the single trial of sucralfate no conclusions can be drawn, and trials of ranitidine show no difference compared to placebo. Meta-analysis of the nosocomial pneumonia incidence reveals a significant result, although this must be interpreted with caution as this analysis contains a large subset of patients from one trial.

This paper highlighted an important point - that little of what we do to prevent stress ulceration is evidence based. There is no conclusive data from any study or from this meta-analysis. The natural conclusion is that further randomised controlled blind studies are required.

\section{Introduction}

The study by Messori et al attempts, by way of performing meta-analyses, to assess or determine the effectiveness of ranitidine sucralfate in the prevention of stress ulceration. It also performs further metaanalysis to assess these treatments and their risk of nosocomial pneumonia. 
Ranitidine and sucralfate are widely used to prevent stress ulceration.Ranitidine is a histamine-2 receptor antagonist and acts by regulation of $\mathrm{HCl}$ production at the parietal cells in the stomach. Sucralfate is an aluminium hydroxide sulphated sucrose complex which coats the gastric surface, anion binding to positively charged proteins. This may prevent diffusion of hydrodgen ions an also stimulates mucus and bicarbonate production and prostaglandin secretion.

The paper aims to provide five separate meta-analyses:

- A-ranitidine versus placebo - rate of bleeding

- B-sucralfate versus placebo - rate of bleeding

- C- ranitidine versus placebo - incidence of nosocomial pneumonia

- D- sucralfate versus placebo - incidence of nosocomial pneumonia

- E- ranitidine versus sucralfate - incidence of nosocomial pneumonia

\section{Methods}

- The meta-analysis search for randomised trials was performed by keyword searching (keywords: stress, pneumonia, ranitidine, sucralfate, randomised controlled trial/random) the following medical literature databases; Medline 1966-2000, Iowa-IDIS system, Drugdex

- Each trial is assessed using a scoring system based on the testing of variables (termed the 'Methodological Quality'). Each appropriate randomised study is rated and given a score based on the following selection criteria; patient selection, patient characteristics, randomisation, blinding, definition of pneumonia and or bleeding.

- Data synthesis - Odds ratios based on the random effect model

\section{Results}

Rate of bleeding:

- A- ranitidine versus placebo; five trials, 398 pts: SD (mean quality score) 6.6; no significant benefit odds ratio $0.95,0.37$ to $2.43, P=0.92$

- $\quad$ B- sucralfate versus placebo; one trial, 54 pts; SD; odds ratio $1.26,0.12$ to $12.9, P=0.7$

Incidence of nosocomial pneumonia: 
- C- ranitidine versus placebo; three trials, 311 pts; SD 6; no significant difference; odds ratio 1.10, 0.45 to $2.66, P=0.84$

- D- sucralfate versus placebo; two trials, 226 pt; SD 6; odds ratio 2.11, 0.79 to 5.64, $P=0.14$

- $\quad$ E- ranitidine versus sucralfate; eight trials, 1825 pts; SD 5.6; odds ratio 1.51,1.0 to 2.29, $P=0.05$

\section{References}

1. Trippoli S, Valani M, Govini M, Corrado A: Bleeding and pneumonia in intensive care patients given ranitidine and sucralfate for prevention of stress ulcer: meta-analysis of randomised controlled trials.

BMJ. 2000, 321: 1103-1107. 